\title{
A new triadotypid insect from the Late Triassic of South Africa
}

Isabelle Deregnaucourt, Torsten Wappler, John M. Anderson, and Olivier Béthoux Acta Palaeontologica Polonica 62 (3), 2017: 613-618 doi:https://doi.org/10.4202/app.00345.2017

Extant odonates (damsel- and dragonflies) represent a small subset of the historical biodiversity of this group. Among their successive stem-groups, the Triadotypomorpha are poorly documented. Herein we describe a new species Reisia rieki from the Molteno Formation (South Africa, Upper Triassic) belonging to this taxon. The comparatively large sample allows a relatively complete description of the wing venation in Triadotypomorpha. We noticed the occurrence of a strongly oblique crossvein located between RA and RP1, a condition documented in some other Pandiscoidalia and which might be of phylogenetic importance. The new species probably inhabited open landscapes and foraged above large water bodies. The documentation of a Gondwanian Triadotypomorpha demonstrates that the group had a worldwide distribution by the Triassic.

Key words: Arthropoda, Odonata, Pandiscoidalia, Triassic, Carnian, Molteno Formation, South Africa.

Isabelle Deregnaucourt [isabelle.deregnaucourt@edu.mnhn.fr] and Olivier Béthoux [obethoux@mnhn.fr ] (corresponding author), Sorbonne Universités, UPMC Univ Paris 06,

MNHN, CNRS, Centre de recherche sur la paléontologie-Paris (CR2P), 57

rue Cuvier, CP38, F-75005 Paris, France. Torsten Wappler [xtwappler@uni-bonn.dexx

], Steinmann Institute, University of Bonn, Nussallee 8, 53115 Bonn, Germany; and [wappler@hlmd.de ], Hessisches Landesmuseum, Friedensplatz 1, 64283 Darmstadt,

Germany. John M. Anderson [jmanderson.gondwana@gmail.com], Environmental Studies Institute, Witwatersrand University, 1 Jan Smuts Ave., Braamfontein, Johannesburg 2000, South Africa.

This is an open-access article distributed under the terms of the Creative Commons Attribution License (for details please see creativecommons.org), which permits unrestricted use, distribution, and reproduction in any medium, provided the original author and source are credited. 
FoF Full text $(754.3 \mathrm{kB})$ 